\title{
207 \\ Beauty Leaf (Calophyllum inophyllum L.), tree: a tree with great economic potential
}

\author{
Subhash Hathurusingha and N. Ashwath \\ Centre for Plant and Water Sciences, Central Queensland University, Rockhampton OLD 4702, \\ Australia
}

Calophyllum inophyllum L. (Clusiaceae) commonly known as Alexandrian laurel or beauty leaf or Domba (in Sri Lanka) is essentially a littoral tree of the tropics, occurring above the high-tide mark along sea coasts of northern Australia and extending throughout Southeast Asia and southern India (Agroforesrey Database 2007). The tree is native to both Australia and Sri Lanka. For many years it has been used by indigenous communities and alternative medicine practitioners. It also has a high demand for its seed oil from cosmetics and pharmaceutical industries.

It is a high potential bio-diesel plant. Seed yields $65 \%$ oil from its dry weight $3744 \mathrm{~kg} / \mathrm{ha}$ from 400 trees (Azam et al. 2005). It has the highest per tree oil yield from 75 plant species tested so far. It can be used in conventional diesel engines (without any alterations) in its pure form or as a blend with mineral oil (Agarwal 2006).

It is also a durable multi-purpose timber (density $\left.560-900 \mathrm{~kg} / \mathrm{m}^{3}\right)($ Timber Species Notes, DPI Queensland 2007). With recently discovered plant properties (anti-HIV and anti-cancer active compounds), Calophyllum inophyllum can be placed amongst the most important multi-purpose trees.

This paper reviews various economically important uses and services of Calophyllum inophyllum L. and areas for future research. This also outlines an ongoing research project "Provenance variations in ecophysiology, growth, performance, seed oil and Calocoumarin-A (anti-cancer agent) content of Calophyllum inophyllum L." that is being carried out in Queensland, Australia and in Sri Lanka.

\section{8 \\ Sustainable Management of Forest Resources in India Through Criteria and Indicator Approach}

\author{
G M Devagiri, T Nethravathi, Sathish and H S Vasudev \\ University of Agricultural Sciences, Bangalore, India \\ College of Forestry, Ponnampet, Kodagu, Karnataka, India
}

The concept of Sustainable Forest Management (SFM) is not new, but has become popular in recent years. SFM encompasses environmental dimension relating to maintenance of the natural resources in perpetuity, economic dimensions for production of goods and services and social dimensions describing involvement of people in decision-making process and equitable benefit sharing. For operationalising SFM it is imperative to have assessment system such that deviations towards or away from sustainability can be ascertained and corrective actions can be taken. The system should evaluate the two main conditions i.e., maintenance of ecosystem integrity and maintenance and enhancement of well being of people.

Criteria and indicators ( $\mathrm{C} \& \mathrm{I}$ ) are the tools for assessing the magnitude and the direction of change in a given forestry situations and provide a forest management information system, which is important for forest managers and other actors for forestry related decision making. C \& I can be used to encourage more holistic thinking when planning forest management activities, and to bring about greater vigor, openness, transparency and accountability in forest management planning, monitoring and reporting. The important eight criteria adopted in some forest divisions of India includes increase in the extent of forest and tree cover, maintenance, conservation and enhancement of biodiversity, maintenance and enhancement of ecosystem function and vitality, conservation and maintenance of soil and water resources, maintenance and enhancement of forest resource productivity, optimization of forest resource utilization, maintenance and enhancement of social, cultural and spiritual benefits and adequacy of policy, legal and institutional framework. Under each of these criteria such as for example under ecosystem function and vitality, the status of natural regeneration is used as an indicator.

Mishra et al. (2004) observed that the people are mostly dependent on trees outside forest, hence reducing the pressure on the natural forest. The sustainability index shows comprehensive impact of various indicators on 